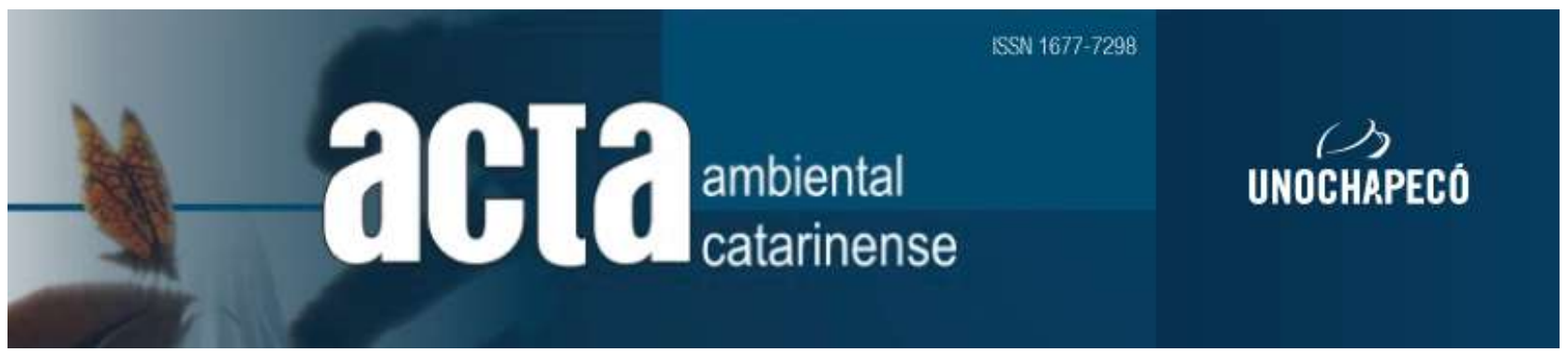

\title{
CaracterizaÇão Socioambiental do Parque Ecológico da LAGOA DA JANSEN, SÃO LUÍS/MA
}

\author{
Paloma Daycy Mendes Silva ${ }^{1}$ \\ Marilena Chaves Silva ${ }^{2}$ \\ Scarleth Karolyne Vieira Leitão ${ }^{3}$ \\ Ana Valéria Pires Muniz ${ }^{4}$
}

\begin{abstract}
Resumo
As Unidades de Conservação são espaços territoriais protegidos legalmente com o intuito de conservar a biodiversidade presente, são áreas apontadas por muitos pesquisadores como únicas formas de florestas a existirem futuramente, visto o crescente avanço da urbanização. Diante dessa realidade, existe uma preocupação em como proteger essas áreas para que de fato elas possam manter sua biodiversidade preservada diante da demanda cada vez maior por ocupação de áreas. Essa preocupação tornou-se objeto de estudo da presente pesquisa, que possui a finalidade de compreender as transformações que ocorrem nessas áreas a partir do avanço da urbanização. Para tal compreensão a Unidade de Conservação escolhida foi o Parque Ecológico da Lagoa da Jansen, que se localiza na Cidade de São Luís/MA na área que abriga boa parte da população com alto poder aquisitivo e uma pequena parcela de comunidades de baixa renda, o que permite uma análise crítica das interferências urbanas em cada camada social. A pesquisa foi desenvolvida em algumas etapas, as quais envolveram o levantamento de bibliografia, visitas na área de estudo, levantamento fotográfico, medições em áreas que possuem ainda vegetação a fim de explicar as transformações urbanas realizadas e como o ambiente local as recebeu. Foram levantados problemas socioambientais tais como: poluição da água, desaparecimento da fauna aquática que outrora servia de alimento para as comunidades residentes, dentre outras problemáticas. O estudo permitiu apontar que somente um projeto em conjunto com Poder Público das áreas social, ambiental, de segurança e econômica podem garantir a perpetuação da Unidade de Conservação.
\end{abstract}

Palavras - chaves: Unidades de Conservação. Urbanização. Ambiente. Sociedade.

\footnotetext{
${ }^{1}$ Graduanda em Engenharia Ambiental. Faculdade Pitágoras - Matriz, PITÁGORAS, Brasil.

${ }^{2}$ Graduanda em Engenharia Ambiental. Faculdade Pitágoras - Matriz, PITÁGORAS, Brasil.

${ }^{3}$ Graduanda em Engenharia Ambiental. Faculdade Pitágoras - Matriz, PITÁGORAS, Brasil.

${ }^{4}$ Engenheira Ambiental. Faculdade Pitágoras - Matriz, PITÁGORAS, Brasil.
} 


\begin{abstract}
The Conservation Units are territorial spaces legally protected in order to conserve the present biodiversity, they are areas pointed out by many researchers as the only forms of forests to exist in the future, given the increasing advance of urbanization. In view of this reality, there is a concern on how to protect these areas so that in fact they can maintain their biodiversity preserved in the face of the increasing demand for occupation of areas. This concern has become the object of study in the present research, which has the purpose of understanding the transformations that occur in these areas as urbanization progresses. For this understanding, the Conservation Unit chosen was the Lagoa da Jansen Ecological Park, which is located in the City of São Luís / MA in the area that houses a large part of the population with high purchasing power and a small portion of low-income communities, the that allows a critical analysis of urban interferences in each social layer. The research was developed in some stages, which involved the bibliography survey, visits in the study area, photographic survey, measurements in areas that still have vegetation in order to explain the urban transformations carried out and how the local environment received them. Socioenvironmental problems were raised such as: water pollution, disappearance of aquatic fauna that once served as food for resident communities, among other problems. The study showed that only a project in conjunction with the Public Authorities in the social, environmental, security and economic areas can guarantee the perpetuation of the Conservation Unit.
\end{abstract}

Key words: Conservation units. Urbanization. Environment. Society.

\section{INTRODUÇÃ̃o}

O Parque Ecológico da Lagoa da Jansen é um dos cartões postais de São Luís, funciona como um ambiente de lazer para as comunidades ao seu entorno e possui em sua área limitada diversos empreendimentos urbanos que funcionam como atrativo para turistas e que impulsionam a economia local. O que não é de conhecimento de muitos é que o Parque Ecológico é uma Unidade de Conservação de Proteção Integral e por isso possui uma rica biodiversidade de espécies da fauna e flora, promovendo dessa maneira à prestação de serviços ambientais essenciais as populações locais.

O Parque Ecológico da Lagoa da Jansen se categoriza como uma Unidade de Conservação de Proteção Integral a partir da Lei Estadual n ${ }^{\circ} 9413$ de 13 de julho de 2011 que institui o Sistema Estadual de Unidades de Conservação da Natureza do Estado do Maranhão. As Unidades de Conservação enquadradas nessa categoria possuem 0 objetivo de proteção à natureza admitindo-se apenas o uso indireto dos seus recursos naturais.

Na década de 70 houve uma expansão urbana, com a construção da Ponte José Sarney que interligou o centro antigo ao bairro de São Francisco, propiciou a urbanização acelerada da orla marítima, tornando-se necessária a implantação de vários acessos adequados à região (LABOHIDRO, 1998). Com essa crescente urbanização desordenada a Lagoa começou a sofrer vários impactos socioambientais, o que torna dificultosa a preservação desse ambiente.

O uso e ocupação do solo do Parque Ecológico da Lagoa da Jansen afeta a dinâmica e equilíbrio ambiental em diferentes proporções, sendo um dos principais fatores causadores de agressões ao meio ambiente local. Esse processo de urbanização se intensifica ainda mais, visto que a área possui em sua circunvizinhança bairros nobres do Município de São Luís, tais como São Francisco, Renascença, Ponta do Farol dentre outros (MASSULO et al., 2014). 
O crescente processo de urbanização na área possui níveis preocupantes diante dos aspectos ambientais e sociais o que exige do Poder Público em todos os níveis da federação, ações que tenham como foco a gestão pública em áreas de proteção ambiental com o objetivo principal de reduzir os conflitos socioambientais e evitando contradições na gestão por parte do Poder Público (RIO BRANCO, 2012).

A partir disto, a presente pesquisa estudou a área de estudo a fim de observar e analisar as alterações ocorridas através da urbanização local, a partir do levantamento dos aspectos ambientais existentes e seus respectivos impactos ao meio ambiente de forma a promover a caracterização atual do local sob aspectos sociais e ambientais. Ao ser promovida esta análise, busca-se aperfeiçoar conhecimentos e despertar o interesse de outros estudos acerca deste tema.

\section{MATERIAL E MÉTOdos}

\section{1 Área de Estudo}

A pesquisa foi desenvolvida no Parque Ecológico da Lagoa da Jansen que foi criado pelo governo do Estado do Maranhão no ano de 1988 pelo Decreto Estadual $n^{\circ} 4478$ de 1988 e desde então se tornou uma área de lazer para a população de sua capital São Luís. A Unidade de Conservação se encontra na região Noroeste da Ilha do Maranhão, mais precisamente no município de São Luís, fica a uma distância de $4 \mathrm{~km}$ do Centro Histórico, entre as coordenadas $02^{\circ} 29^{\prime} 07^{\prime \prime} \mathrm{S}$ e $44^{\circ} 18^{\prime}$ 02" W (TARGINO, 1999, p. 16). Na figura 01 pode-se observar o mapa de localização da Unidade de Conservação com relação ao Município ao qual a mesma pertence, bem como a relação da localização do mesmo com o Brasil.
Figura 01 - Mapa de Localização do Parque Ecológico da Lagoa da Jansen.

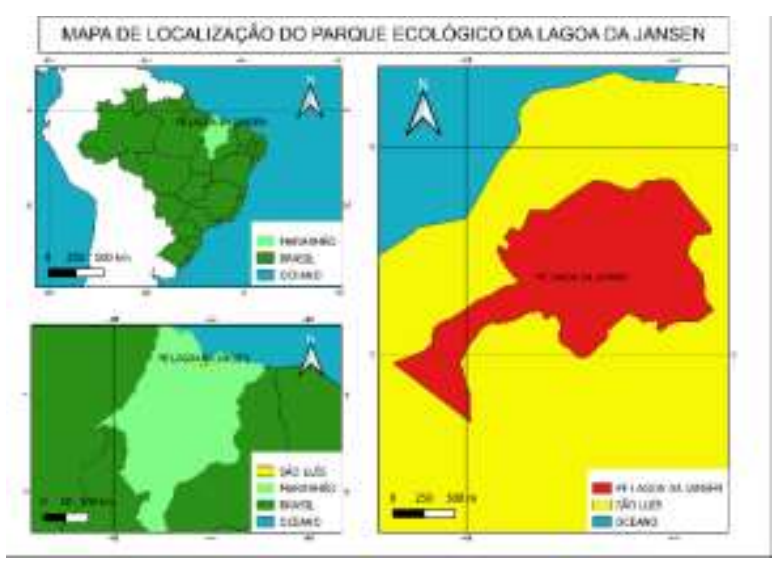

FONTE: Adaptado de Nereus e Sema (2020).

\subsection{Materiais}

Para as visitas técnicas utilizou-se de materiais para registro fotográfico, gravação de voz e demais formas de registro de observações. Para tais registros forma utilizados tais ferramentas: uma câmera de um aparelho celular da marca Samsung, gravador de voz digital da marca Knup, pranchetas para suporte, papel, canetas e fita métrica.

\subsection{Métodos}

A primeira fase da pesquisa se constituiu em visitas na referida área de estudo a fim de observar as estruturas urbanas presentes na mesma bem como as espécies da fauna e flora existentes no local, esse levantamento foi realizado durante quatro visitas in loco, sendo duas no período da manhã e duas no período da tarde, em todos os períodos o tempo do Município de São Luís encontrava-se ensolarado, o intervalo de tempo entre cada data foi de sete dias.

A segunda fase da pesquisa caracterizou-se pela como aparelho gravador de áudio para que todos os pontos avistados fossem analisados organização de todos os dados obtidos, os registros em áudio e os 
fotográficos a fim de tornar a análise dos mesmo mais rápida e objetiva.

A terceira fase dividiu-se no conjunto de análise dos dados e complementação dos mesmos a partir de pesquisas já realizadas na área, assim foi realizado um levantamento bibliográfico para embasar as análises realizadas na presente pesquisa bem para confrontar observações realizadas anteriormente em estudos e as encontradas atualmente no Parque. A partir da bibliografia consultada as análises aqui levantadas puderam servir para comparar o ambiente durante um período de tempo considerável, levando-se em consideração o ápice do processo urbano local.

\section{RESUltados E DiscuSSÃo}

\subsection{Caracterização da Mata Ciliar e do Manguezal do Parque Ecológico da Lagoa da Jansen}

A mata ciliar possui funções fundamentais para promover o melhor equilíbrio aos ecossistemas presentes em um ambiente, através de sua proteção é possível proteger corpos d'água de assoreamento e contaminação, visto que a vegetação consegue filtrar a água anteriormente a sua chegada aos rios e protege o solo da força da água proveniente de enxurradas, o que dificulta o desprendimento das partículas do solo e transporte para os curso d'água.

Através da mata ciliar também é possível manter o fluxo migratório das espécies, ou seja, há uma movimentação muito maior entre as espécies de um ambiente a outro o que é um fator fundamental para manter o fluxo genético e diminuir a extinção de determinada espécie, por exemplo. A variabilidade genética é fundamental para a adaptação das espécies ao ambiente e possibilidade de perpetuação.

A partir da importância desse tipo de vegetação para a conservação de um ambiente, observa-se que no Parque Estadual da Lagoa da Jansen essa vegetação já sofreu grandes transformações durante o período do processo de urbanização local e que se perpetua até os dias atuais. Atualmente são poucas as áreas ao redor da lagoa que ainda possuem cobertura florestal, o que representa um dos fatores primordiais para as transformações ambientais existentes.

Apesar da área ser categorizada como uma Unidade de Conservação, a classificação não impediu que a urbanização chegasse ao local e promovesse a modificação da paisagem quase que totalmente. Para Santos et al. (2010) esse fato ocorre devido essas áreas não possuírem métodos de utilização adequada dos recursos naturais bem como do uso e ocupação do solo.

Sem possuir a devida proteção garantida pela manutenção de sua mata ciliar, o corpo d'água existente sofre com a disposição de resíduos que são carreados pelos ventos e pela água da chuva, o que promove séria alterações na qualidade da água. Sayre (2003) em seu estudo caracterizou a vegetação da área composta por herbáceas, bosques, bosques esparsos e mata arbustiva. No estudo aponta-se que os bosques possuem árvores de até 5 metros de altura e ocupam até $60 \%$ de toda a área. Porém, atualmente esse tipo de árvores de grande porte apresenta uma taxa de ocupação bem menos que a apontada em 2003.

Segundo a Lei Feral no 12651 de 25 de maio de 2012, as faixas de vegetação nativa para lagos e lagoas naturais que devem ser protegidas ao seu redor é de largura mínima de 30 metros em zonas urbanas. $\mathrm{Na}$ área de estudo se observa que em diversos pontos que essa faixa de vegetação é inexistente e onde ainda existe a área é de apenas 17 metros, ou seja, totalmente contrária a legislação. Observa-se que a área que era para existir vegetação foi tomada por bares e espaços de comércio local, na figura 02 observa-se um dos poucos pontos onde foi localizada mata ciliar, porém sem a medida estipulada em lei. 
Figura 02- Mata ciliar ao redor da Lagoa da Jansen.

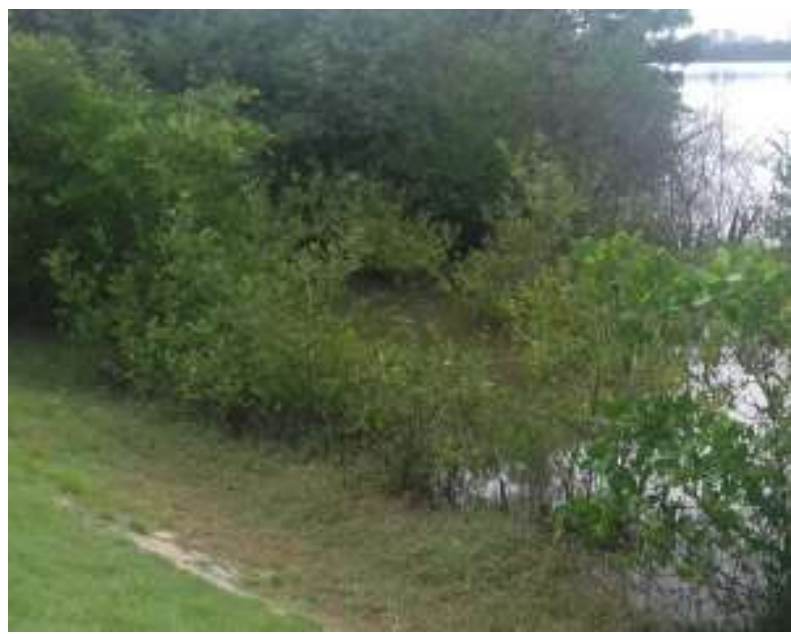

FONTE: Dados da pesquisa, 2020.

No contexto do Parque Estadual da Lagoa da Jansen outro fator que deve ser considerado primordial à sua preservação e análise atual é a presença do ecossistema manguezal, que também é uma Área de Preservação Permanente. Segundo o Instituto Chico Mendes de Conservação da Biodiversidade - ICMBio (2018) o manguezal é o ecossistema mais produtivo de todo o planeta e promovem uma regulação ambiental através dos diversos serviços ambientais por ele ofertados.

Sayre (2003) identifica em seu estudo que a cobertura de vegetação predominante na área é típica do ecossistema mangue, o autor aponta que essa cobertura vegetal já se encontrava bastante degradada. Atualmente, após 17 anos do estudo realizado pelo autor, observou-se que essa degradação ocorreu de maneira ainda mais acentuada e que são pouquíssimas as árvores de mangue presentes no local, a grande maioria foi desmatada para construções.

Segundo Santos (2009) no Parque Ecológico da Lagoa da Jansen existia aproximadamente 160 ha de mangue, sendo 15,6 de apicuns 11,3 faixas de transição. Sabese que a vegetação típica do ecossistema manguezal é bem resiliente, graças a esse tipo de adaptação essa vegetação ainda consegue resistir em meio a todo um entorno de construções urbanísticas. Porém, sabe-se que essa capacidade de adaptação é limitada, por isso, a necessidade de se promover maneiras para a preservação da vegetação no local.

$\mathrm{O}$ presente estudo identificou a presença de dois tipos de mangue predominantes: o preto e o branco. Esses tipos de mangue possuem características muito parecidas, como o tipo de raízes das plantas, que são aéreas, chamadas raízes pneumatóforos, além de as plantas respirarem pelas folhas, pelo caule e pela raiz.

Pode-se observar que a mata ciliar presente na Lagoa da Jansen é representada pela vegetação do ecossistema manguezal, conforme mostra a Figura 03, dessa maneira toda as funções mencionadas que são desempenhadas pela mata ciliar são realizadas pelo manguezal, o que torna suas características ainda mais fundamentais para proteção da natureza que ainda existe na região. O mangue protege a lagoa do processo de lixiviação, que é quando a água da chuva carrega os resíduos presentes no solo e os direciona para um recurso hídrico. A ausência dele na área de estudo acarreta na disposição desses resíduos diretamente na lagoa.

Figura 03- Área de Manguezal no entorno da Lagoa da Jansen.

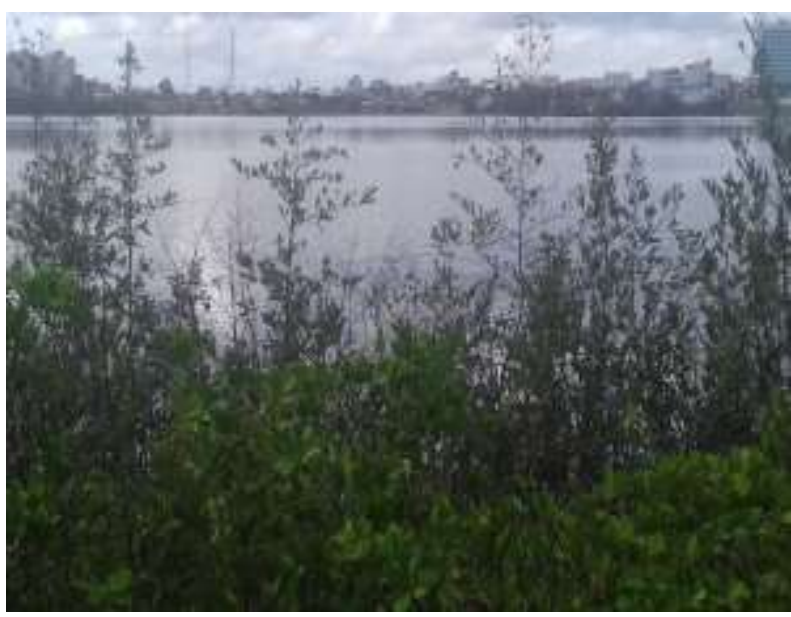

FONTE: Dados da pesquisa, 2020. 


\subsection{Aspectos e Impactos Ambientais no Parque Ecológico da Lagoa da Jansen}

O Parque Estadual da Lagoa da Jansen é uma área que serve de lazer para toda a população da cidade de São Luís, bem como de turistas vindos de outros estados brasileiros. E, se tratando de uma área de lazer com alta concentração de pessoas, sofreu grandes investimentos de cunho comercial, o que possibilitou que no entorno da Lagoa, existissem vários condomínios, quiosques, bares, casas de festas, dentre outras estruturas urbanas para promoção de lazer da região que promovem diversão para a população e o intenso fluxo do comércio local, na Figura 04 pode-se observar os empreendimentos construídos as margens da lagoa.

Figura 04 - Área externa de um dos bares dentro do Parque.

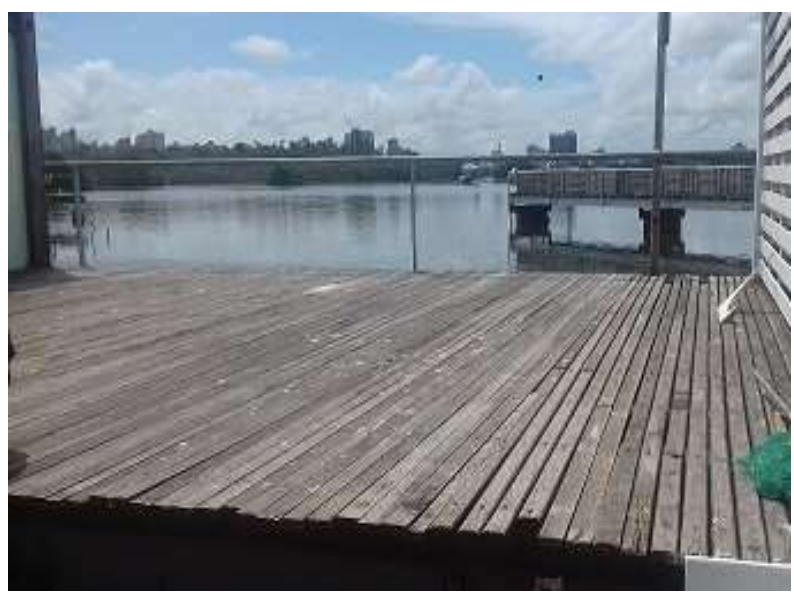

FONTE: Dados da pesquisa, 2020.

Com toda essa demanda comercial, o local possui muitos aspectos ambientais, que segundo a Norma Brasileira 14001 (2004) são elementos das atividades, produtos ou serviços de uma organização que podem interagir com o meio ambiente e gerar impactos ambientais.

Nesse contexto, os aspectos ambientais elencados ao chegarem ao meio aos ecossistemas presentes no Parque Ecológico da Lagoa da Jansen interagem com os mesmos e provocam modificações. Essas modificações são chamadas de impactos ambientais, que são os principais responsáveis pela mudança das características naturais dos ambientes e consequente desequilíbrio ambiental. Na Lagoa da Jansen existem muitas alterações, o principal impacto encontrado foi acerca do corpo d'água existente que sofre com o despejo inadequado de efluentes doméstico.

$\mathrm{Na}$ lagoa pode-se perceber a ocorrência do processo eutrofização, que é um processo natural dos recursos hídricos fechados, porém na Lagoa da Jansen esse processo ocupa lugar de impacto ambiental, uma vez que os esgotos dos condomínios e dos pontos comerciais do local, não possuem uma destinação correta e acabam ingressando no recurso hídrico por meio de vários pontos de drenagem pluviométrica existentes na Lagoa, que acabam servindo como geradores de efluentes domésticos e industriais.

A eutrofização é motivada pelo aumento de nutrientes como nitrogênio e fósforo em grande quantidade em um corpo hídrico o que acelera a proliferação de algas que podem produzir substâncias tóxicas e nocivas à saúde. Esse ambiente torna as águas contaminadas e prejudicam não somente a fauna existente, tais como a morte de peixes, mas também representam um perigo para a população que utiliza a água para consumo, por exemplo. Com a proliferação das algas na superfície das águas a passagem de luz também é dificultada para o fundo, fato que prejudica $\mathrm{o}$ processo de fotossíntese e consequentemente disponibilidade de oxigênio nas camadas mais profundas da água (BARRETO et al., 2013).

No contexto da lagoa ocorre uma alta concentração de resíduos orgânicos, provenientes de esgoto doméstico local, o que consequentemente faz com que tenha grande quantidade de nutrientes e o processo de eutrofização aconteça de maneira acelerada, funcionando da seguinte forma: as algas fitoplâncton se alimentam desses nutrientes, como são organismos unicelulares, elas se 
reproduzem rapidamente e em poucos minutos já se tornam milhares cobrindo a superfície da Lagoa formando manchas verdes. Essas algas produzem oxigênio que serve tanto para sua respiração como de outros organismos, como peixes e bactérias aeróbias. Porém, a produção de oxigênio não é suficiente para todos esses organismos, e as algas acabam indo para o fundo da Lagoa junto com outros detritos, provocando $\mathrm{o}$ assoreamento do corpo d'água.

O Parque Ecológico da Lagoa da Jansen também possui odores bem desagradáveis que incomodam toda a população que utiliza o espaço para lazer ou mesmo reside na região. Esse mau odor também é explicado pelo processo de eutrofização, uma vez que, quando acaba o oxigênio entra no processo outro organismo, as bactérias anaeróbias, que consomem a matéria presente na lagoa e liberam gases como o gás Metano e o gás Sulfídrico, este último responsável pelo odor desagradável no local.

A geração de resíduos sólidos é outra problemática local, a coleta de lixo é realizada de maneira periódica pela Prefeitura, porém ela não é suficiente, pois é possível avistar nas margens da lagoa bem como em todo seu entorno muitos resíduos sólidos urbanos provenientes da falta de educação ambiental e consciência da população. Todos esses resíduos sólidos com o processo de lixiviação, que acontece no período chuvoso, acabam sendo levados para o fundo da lagoa, o que contribui para a poluição do recurso hídrico bem como para a redução da sua profundidade.

$\mathrm{Na}$ Figura 05 é possível observar que os empreendimentos comerciais da região se encontram situados praticamente dentro da lagoa, e os canos que coletam os seus efluentes líquidos estão ligados diretamente com o recurso hídrico. O que nos possibilita dizer que estes empreendimentos são responsáveis diretos pela alta concentração de efluentes orgânicos na lagoa, o que origina todo o processo de eutrofização mencionado ao longo do texto.

Figura 05 - Empreendimento comercial construído a margem da lagoa.

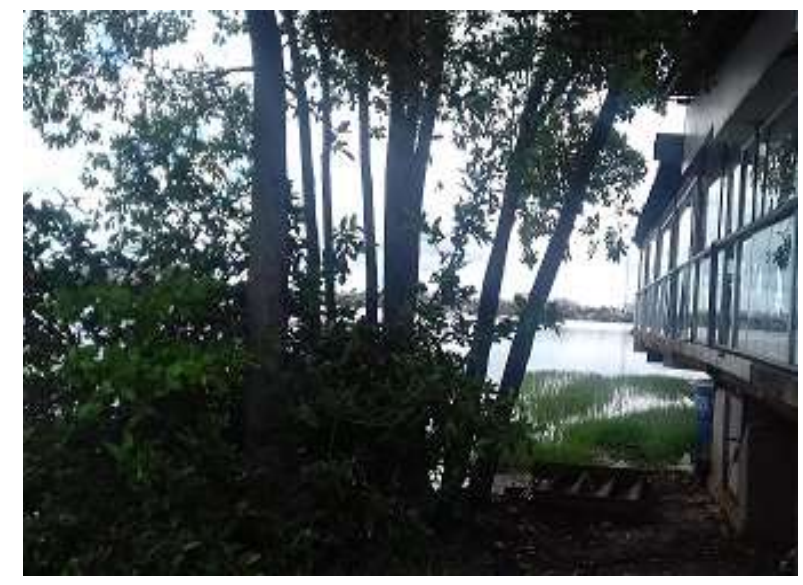

FONTE: Dados da pesquisa, 2020.

\subsection{Impactos Sociais no Parque Ecológico da Lagoa da Jansen}

O Parque Ecológico da Lagoa da Jansen é responsável pelo grande fluxo de pessoas e turista nessa região de São Luís, ele interage diretamente com a população que vive no local. Para Rio Branco (2012) a partir da década de 1970 começaram a surgir na paisagem urbana da cidade diversas formas de habitação que em sua grande maioria são habitações irregulares que abrigam populações de baixa renda e que vivem em condições insalubres com moradias que não possuem o básico para a qualidade de vida humana. Apesar da poluição presente no local, muitas comunidades que ali residem nas condições aqui já mencionadas, retiram todos os dias da lagoa o necessário para garantir a alimentação da sua família.

A poluição desse recurso afeta a vida dessas comunidades, uma vez que com processos de eutrofização e lixiviação existem impactos que causam a diminuição da biodiversidade do local. Dessa maneira, fica cada vez mais difícil garantir que os pescadores tenham o que pescar, pois, a cada ano tem-se um grande índice de mortandade 
dos peixes. Essa poluição também permite que esses peixes se alimentem de matéria encontrada na lagoa, e muitas vezes possuem substâncias que podem fazer mal à saúde humana, não é recomendável se alimentar de organismos que vivem em um local com um alto índice de poluição.

Na Figura 06 é possível observar que as comunidades locais ainda praticam a atividade pesqueira no local. Muitas dessas pessoas não têm o conhecimento do mal que esse alimento pode ocasionar à saúde humana, alguns até tem esse conhecimento, porém, não possuem outra forma de garantir o seu sustento e de sua família. Costa (2014) traz que essas desigualdades socioeconômicas fazem parte do que é hoje o espaço delimitado pelo Parque Ecológico da Lagoa da Jansen e que a prioridade de investimentos para a área são alheias a qualidade ambiental e a real realidade social existente.

Figura 06- Pescadores na Lagoa da Jansen.

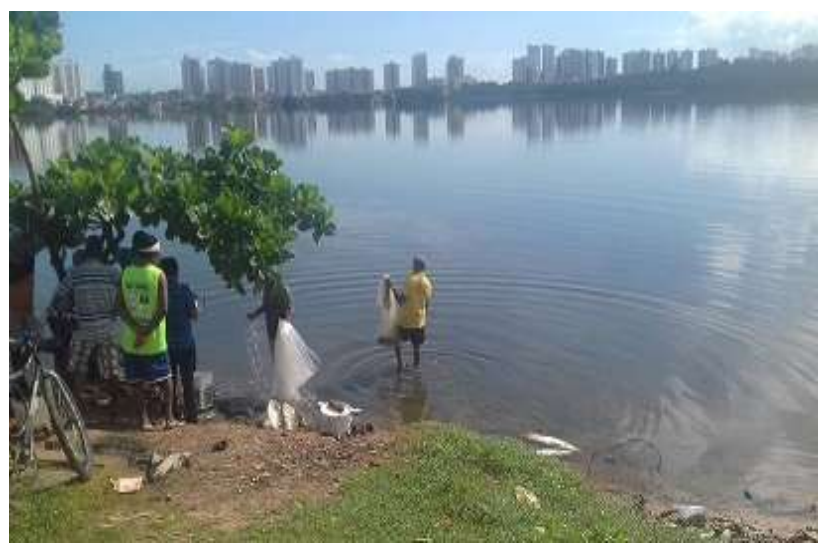

FONTE: Dados da pesquisa, 2020.

Problemas sociais de cunho da segurança pública também existem no local devida as áreas de manguezais que ainda possuem vegetação servirem de esconderijo para assaltantes em períodos com pouco movimento o que facilita a prática do crime. Outros aspectos que potencializam esse crime são a falta de iluminação adequada, o que torna esse ambiente uma área considerada de risco e a falta de policiamento local.
Muitos indivíduos utilizam a área para fazer corrida, caminhada, passear com seus animais de estimação, e na área de manguezal é possível que assaltantes se escondam entre a vegetação e acabem surpreendendo esses indivíduos. Nas visitas in loco pode-se perceber que para evitar esse tipo crime o método utilizado foi o desmatamento dessas áreas florestadas pelo manguezal, o que se torna um meio considerado descabido do ponto de vista ambiental e social, uma vez que, a criminalidade existe por questões bem mais profundas que um simples desflorestamento não é capaz de resolver.

Os bares situados dentro da lagoa também oferecem um grande risco aos seus clientes, pois, eles se encontram sobre uma construção de madeira que fica em contato direto com a lagoa, por isso, está sempre úmida. Com a falta de manutenção essa estrutura pode vir a ocasionar acidentes graves. É evidente que as estruturas apresentadas pelos empreendimentos não possuem manutenção e nem sofrem fiscalizações por parte dos órgãos responsáveis pelo local.

Ainda no entorno do Parque Ecológico da Lagoa da Jansen é possível distinguir duas realidades distintas, onde uma área possui uma bela infraestrutura, com prédios luxuosos, bares e casas de festas de alto padrão em contrapartida a outra área possui uma infraestrutura precária, onde a população vive em um estado deplorável, as casas que se situam nessa área sofrem muito mais com os problemas ocasionados pela poluição na lagoa. As alterações ocasionadas na Laguna da Jansen a tornam um local de risco para novos empreendimentos, levando-se em conta que as mudanças ambientais aumentaram os casos de alagamentos nas áreas vizinhas, demostrando o contraste socioambiental de edifícios de luxo e casebres que se encontram na região periférica (RIO BRANCO, 1997).

Ressalta-se que o PE da Lagoa da Jansen se apresenta atualmente como uma Unidade de Conservação caracterizada apenas para turismo e recreação, visto que foram 
instaladas estruturas para tal uso. Dessa maneira, a maioria da população não possui o conhecimento sobre a importância ambiental da área, esse fato pode ser explicado por Silva; Melo \& Souza (2011) que trazem que a instalação de atrativos turístico promove um entrave na conservação ambiental, visto que não consideram a participação da população no processo e uso dos mesmo promovendo ainda uma diferença entre o uso do território entre as comunidades de baixa renda e os de maior poder aquisitivo.

\subsection{Conclusão}

Diante da caracterização feita na presente pesquisa, pode-se afirmar que o Parque Ecológico da Lagoa da Jansen dispõe de grande diversidade de atrativos naturais e culturais, que podem ser utilizados de forma planejada, para o desenvolvimento de práticas esportivas e turísticas, a fim de trazer melhorias para o meio ambiente e para a comunidade local, promovendo uma fácil circulação da economia local.

Entretanto, as consequentes transformações do meio ambiente natural na Lagoa da Jansen, têm provocado um esquecimento no que diz respeito aos ecossistemas locais e gerado pelos intensos processos de urbanização ocorrido na área litorânea. Dessa maneira, esses processos de ocupação irregular na orla e as crescentes construções de prédios de grande porte que despejam esgoto doméstico na lagoa, estão deixando a mesma em progressivo processo de eutrofização, que causa destruição da fauna e da flora e transforma alguns locais da lagoa em esgoto a céu aberto.

Desse modo, sugere-se a necessidade de implantação de um projeto de manejo hidráulico que possa garantir a renovação constante da água armazenada na lagoa. Esse projeto aponta para a construção de comportas que permitirá a descargas d'agua no fundo da lagoa. O resultado esperado é a eliminação do odor desagradável que se encontra na mesma. E aliado a isto, a instalação de aeradores de ação superficial que vão servir para oxigenar a zona aeróbica, melhorando a qualidade de efluentes, além do oferecimento de saneamento básico por parte do poder público responsável.

Diante dos apontamentos mencionados finaliza-se a pesquisa com a indicação de algumas melhorias que se aplicadas na área podem trazer bons resultados quanto a relação entre o meio ambiente e qualidade de vida humanas, sendo estas: implementação de sistema de tratamento de efluentes, programa de educação ambiental, programa de saneamento ambiental, monitoramento da qualidade da água e controle das espécies locais. Visto ainda a categoria que a Unidade de Conservação apresenta atualmente, como sendo de Proteção Integral, infere-se ainda um estudo por parte do órgão responsável para adequação de categoria, visto que a mesma não possui características que lhe assegurem dentro desse tipo de categoria.

\section{REFERÊNCIAS}

ASSOCIAÇÃO BRASILEIRA DE NORMAS TÉCNICAS. NBR 14001: Sistema de Gestão Ambiental requisitos com orientação de uso. Rio de Janeiro, p. 02. 2004. Disponível

em: <http://www.madeira.ufpr.br/disciplinasg hislaine/iso-14001-2004.pdf>. Acesso em 15 de fev. de 2020.

BARRETO, LV; BARROS, FM; BONOMO, P; ROCHA, FA; AMORIM, JS. Eutrofização em rios brasileiros. Centro Científico Conhecer. Enciclopédia Biosfera. Goiás, 2013. Disponível em: <https://www.conhecer.org.br/enciclop/2013 a/biologicas/EUTROFIZACAO.pdf $>$. Acesso em 02 de mar. de 2020. 
BRASIL. Lei n ${ }^{\circ} 12651$ de 25 de maio de 2012. Dispõe sobre a proteção da vegetação nativa e dá outras providências. Presidência da República, Casa Civil, Subchefia de Assuntos Jurídicos. Disponível em: <http://www.planalto.gov.br/ccivil_03/_ato2 011-2014/2012/lei/112651.htm>. Acesso em 05 de jan. de 2020 .

COSTA, RHS. Configuração Socioambiental da Laguna da Jansen: São Luís do Maranhão. Anais do VII Congresso Brasileiro de Geógrafos. Espirito Santo, 2014. Acesso em: <http://www.cbg2014.agb.org.br/resources/a nais/1/1405965524_ARQUIVO_ArtigoparaC BG2014.pdf>. Acesso em 16 de mar. de 2020.

Instituto Chico Mendes de Conservação da Natureza - ICMBio. Atlas dos manguezais do Brasil. Brasília, 2018. Disponível em: <https://www.icmbio.gov.br/portal/images/st ories/manguezais/atlas_dos_manguezais_do_ brasil.pdf>. Acesso em 03 de fev. de 2020.

MASSULO YAG; FERREIRA, ARF; SANTOS, AF; SOARES, ABC; FERREIRA, AP. Análise multitemporal do uso e ocupação do solo na Lagoa da Jansen-MA. V CONGRESSO BRASILEIRO DE GESTÃO AMBIENTAL, 2014, Belo Horizonte. Anais Eletrônicos... Belo Horizonte: IBEAS, 2014. Disponível em:< https://www.ibeas.org.br/congresso/Trabalho s2014/XI-077.pdf >. Acesso em 10 de jan. de 2020 .

Núcleo de Economia Regional e Urbana da Universidade de São Paulo - NEREUS. Shapes files dos Estados Brasileiros. São Paulo, 2020. Disponível em: <http://www.usp.br/nereus/?dados=unidadesfederativas $>$. Acesso em 23 de maio de 2020.
Secretaria de Estado do Meio Ambiente, Departamento de Proteção da Biodiversidade. Cadernos da Mata Ciliar $n^{\circ}$ 1. São Paulo, $2009 . \quad$ Acesso em: <https://www.passeidireto.com/arquivo/1845 8804/cadernos-da-mata-ciliar-preservacao-erecuperacao-das-nascentes $>$. Acesso em 15 de mar. de 2020.

Secretaria de Estado de Meio Ambiente Recursos Naturais - SEMA. Superintendência de Biodiversidade e Áreas Protegidas. Shape files das Unidades de Conservação Estaduais. Maranhão, 2020.

SILVA, MSF; MELO \& SOUZA, R. Território usado em áreas protegidas e atrativos turístico: exploração ou conservação ambiental? Revista Nordestina de Ecoturismo, Aquidabã, v. 4, n.2, p. 27-39, 2011.

RIO BRANCO, Washington Luís Campos. Política e gestão ambiental em áreas protegidas em São Luís - Maranhão: o parque ecológico da Lagoa da Jansen. Presidente Prudente,

2012. Disponível em: $<$ http://www2.fct.unesp.br/pos/geo/dis_teses/ $12 / \mathrm{dr} /$ washington.pdf $>$. Acesso em $20 \mathrm{de}$ fev. de 2020 .

RIO BRANCO, Washington Luís Campos. Estudo ecológico humano da comunidade da laguna da Jansen: núcleo de Formação pioneira e palafitação. Dissertação de mestrado em Políticas Públicas. Universidade Federal do Maranhão. São Luís, 1997. Disponível em: 〈http://www.periodicos.capes.gov> Acesso em 17 de mar. de 2020. 
SANTOS, BAMO; DOBBERT, LY; FEITOSA, AC. Dinâmica da Paisagem do Parque Ecológico da "Lagoa da Jansen". VII Simpósio Nacional de Geomorfologia. São Paulo, 2010. Disponível em: <http://lsie.unb.br/ugb/sinageo/8/2/12.pdf>. Acesso em 15 de jan. de 2020.

SANTOS, BAMO; MASSULO, YAG. Avaliação dos Planos de revitalização do entorno da Lagoa da Jansen. IV Jornada Nacional de Políticas Públicas. Universidade Federal do Maranhão. São Luís, 2009. Disponível em: <http://www.joinpp.ufma.br/jornadas/joinppI V/eixos/7_desenvolvimentoregional/avaliacao-dos-planos-derevitalizacao-no-entorno-da-laguna-dajansen.pdf>. Acesso em 06 de fev. de 2020.

SAYRE, R. et al. Natureza em Foco: Avaliação Ecológica Rápida. Virginia, The Nature Conservation, Arlington. Disponível em:

<https://www.icmbio.gov.br/portal/images/st ories/imgs-unidades-

coservacao/naturezaemfoco.pdf > . Acesso em 22 de maio de 2020.

TARGINO, SRB. A urbanização da Laguna da Jansen e sua inserção no cenário turístico de São Luís. 1999. 60p. Dissertação (Especialização em Planejamento Ambiental) -Programa de Especialização. Escola de Geografia. Universidade Federal do Maranhão, São Luís, 1999.

Submissão: 09/04/2020.

Aceite: 28/05/2020. 